ORIGINAL

\title{
PROPAGACIÓN CLONAL IN VITRO DE Eucalyptus pellita F. Muell A PARTIR DE ÁRBOLES PLUS
}

\section{IN VITRO CLONAL PROPAGATION OF Eucalyptus pellita F. MUELL FROM PLUS TREES}

\author{
Dagoberto Castro R¹, Gustavo A. Sánchez R . \\ Recibido para evaluación: Febrero 6 de 2010 - Aceptado para publicación: Junio 8 de 2010
}

\begin{abstract}
RESUMEN
El árbol de eucalipto (Eucalyptus pellita) es un recurso forestal que representa una importante oportunidad para el fomento de reforestación en la Orinoquia colombiana. Para la propagación clonal de árboles seleccionados por sus características sobresalientes de crecimiento y calidad de la madera se requiere desarrollar estrategias para lograr su eficiente multiplicación. El objeto del presente trabajo fue el de propagar árboles plus de $E$. pellita F. Muell, mediante la técnica de cultivo de tejidos vegetales in vitro. Para la fase de establecimiento se empleó como fuente de explantes segmentos nodales obtenidos a partir de brotes epicórmicos de árboles plus. En condiciones de total asepsia se realizó una desinfección con etanol al $70 \%$ durante un minuto, seguido por una inmersión en hipoclorito de sodio al 1\% durante 15 minutos. La siembra se realizó en el medio de Murashige y Skoog obteniéndose hasta un $70 \%$ de cultivos libres de contaminación. Para la proliferación se evaluó el efecto de diferentes concentraciones de BAP, donde las dosis de 0,25 y 0,5 $\mathrm{mg} \mathrm{L}^{-1}$ permitieron obtener 8,83 y 7,88 brotes por explante en 30 días. El enraizamiento se logró cuando se adicionó al medio de cultivo $1 \mathrm{mg} \mathrm{L}^{-1}$ de AIB con un $80 \%$ de brotes que formaron raíces. Cuando las plántulas se llevaron a aclimatización en un sustrato compuesto por turba en condiciones de riego por microaspersión automatizado, se obtuvo un $100 \%$ de supervivencia.
\end{abstract}

Palabras clave: Eucalyptus pellita, micropropagación, enraizamiento in vitro, aclimatización.

\begin{abstract}
The eucalyptus tree (Eucalyptus pellita) is a forester source that represents an important opportunity for the reforestation development in the Colombian Orinoquia. For the clonal propagation of trees selected by their excellent characteristics, growth and quality of the wood is required to develop efficient multiplication strategies. The objective of the present work was to propagate plustrees of E. pellita F. Muell, by techniques of plant tissue culture in vitro. For the establishment phase, nodal segments obtained from epicormic buds of plus trees were used as source of explants. Under aseptic conditions explants were disinfected with $70 \%$ ethanol during one minute, followed by immersion in 1\% sodium hypochlorite during 15 minutes. Explants were planted in Murashige and Skoog media, obtaining up to $70 \%$ of the cultures free of contamination. For
\end{abstract}

Universidad Católica de Oriente, Sector 3 Carrera 46 No. 40B-50 Rionegro, Antioquia AA. 008, Cel. 3136524137 Email: dcastro@uco.edu.co, biotecnologia.aux@uco.edu.co 
proliferation, the effect of different BAP concentrations was evaluated. BAP at 0,25 and $0,5 \mathrm{mg} \mathrm{L}^{-1}$ yielded 8,83 and 7,88 shoots per explant in 30 days, respectively. An $80 \%$ rooting was achieved by adding $1 \mathrm{mg} \mathrm{L}^{-1}$ of AIB to the culture media. For acclimatization plantlets were transplanted in plastic trays containing peat moss under automatic mist condition, and $100 \%$ of survival was obtained.

Keywords: Eucalyptus pellita, micropropagation, rooting in vitro, acclimatization.

\section{INTRODUCCIÓN}

Eucalyptus pellita es una especie forestal originaria de Australia que ha demostrado su potencial para programas de reforestación en la región de la Orinoquía colombiana. En el departamento del Casanare en evaluaciones realizadas durante diez años esta especie presentó volúmenes de hasta $350 \mathrm{~m} 3$ ha $^{-1}$, con unas características sobresalientes de rectitud de fuste y de propiedades físico mecánicas de la madera (Gasca 2006). Debido a su rectitud, conicidad, poca presencia de nudos, y resistencia, E. pellita es una especie importante para la construcción fina, con un gran potencial en el inmunizado (postes de tendidos eléctricos, postes para cerca, polines para ferrocarril, postes para corral). Igualmente, el tamaño de la copa y la disposición de las hojas, permiten utilizarla en sistemas silvopastoriles y cercas vivas, lo que la convierte en una especie promisoria para la región.

En el desarrollo de las investigaciones realizadas por Refocosta se han seleccionado árboles semilleros de la especie, a partir de los cuales se han sembrado 186,4 ha en el proyecto Villanueva (Casanare) y se ha logrado la identificación de árboles con características superiores. Para fijar la ganancia genética de estos árboles se requiere realizar la propagación clonal. Sin embargo, el problema que se presenta es el bajo porcentaje de enraizamiento de estacas que en promedio corresponde al $20 \%$ lo cual hace que operativamente la reproducción vegetativa no se pueda emplear (Gasca 2006).

En general para la multiplicación a gran escala de eucaliptos, las técnicas de propagación convencional son aún las que más se utilizan (Trindade y Pais 1997); sin embargo, la propagación mediante estacas es complicada y el enraizamiento es difícil. De acuerdo con McComb y Bennett (1986) la micropropagación puede ser una alternativa cuando la propagación convencional es difícil de lograr, existen problemas de revigorización y amplificación de híbridos. Las técnicas de micropropagación mediante la proliferación de brotes adventicios (Gupta et al. 1983; Watt et al. 2003; Gomes y Canhoto 2003) han sido aplicadas para la multiplicación in vitro de mirtáceas. Entre los resultados comunes de estos autores se destaca la utilización de las citoquininas BAP o Kinetina para la proliferación con tasas de multiplicación de 4 a 10.

Las técnicas del cultivo de tejidos se han empleado para la propagación de clones con características superiores, el intercambio de germoplasma y en la actualidad se utiliza esta técnica para seleccionar somaclones in vitro tolerantes a enfermedades, salinidad, frío y otros factores ambientales. La transformación 
genética de clones seleccionados es una importante herramienta para el desarrollo de nuevos genotipos, con características deseables, tales como tolerancia a insectos y herbicidas, esterilidad masculina y reducción en los contenidos de lignina (Berrueto et al. 1999).

El objetivo del presente trabajo fue el de establecer la propagación vegetativa de árboles plus de Eucalyptus pellita F. Muell, mediante la técnica de cultivo de tejidos vegetales in vitro.

\section{MATERIALES Y MÉTODOS}

\section{Material vegetal}

El material vegetal correspondió a árboles "plus" mayores de diez años de E. pellita seleccionados en la empresa Reforestadora de la Costa "REFOCOSTA S.A", localizada en Villanueva (Casanare). Estos árboles se derribaron o anillaron para la inducción de brotes epicórmicos, los cuales se llevaron a condiciones de invernadero en cámara húmeda para su enraizamiento y para desarrollar plantas madres para la micropropagación.

\section{Desinfección y establecimiento in vitro}

Para el establecimiento del material vegetal en condiciones in vitro, se tomaron como fuente de explantes iniciales segmentos nodales con dos a tres entrenudos y un tamaño aproximado de ocho centímetros de longitud de las plantas procedentes de brotes epicórmicos. En condiciones de total asepsia en cámara de flujo laminar, se realizó una inmersión en etanol al $70 \%$ durante 1 minuto y luego se sumergieron en hipoclorito de sodio al $1 \%(\mathrm{v} / \mathrm{v})$ con una gota de tween 20 durante 15 minutos. Los explantes se lavaron tres veces con agua destilada estéril y se sembraron en el medio de cultivo. Para todos los casos como medio básico de cultivo se emplearon las sales minerales Murashige y Skoog, 1962 (MS) a las cuales se le adicionó 0,1 $\mathrm{mg} \mathrm{L}^{-1}$ de BAP, sacarosa $30 \mathrm{~g}$ $\mathrm{L}^{-1}$, ácidos cítrico y ascórbico $50 \mathrm{mg} \mathrm{L}^{-1}$ cada uno, vitaminas MS y agar 2,4 $\mathrm{g} \mathrm{L}^{-1}$. El pH del medio de cultivo se ajustó a 5,8 00,1 con $0,1 \mathrm{~N}$ de $\mathrm{KOH}$ y posteriormente, se esterilizó a 121 ${ }^{\circ} \mathrm{C}$ durante 20 minutos. Después de la siembra los explantes se incubaron en condiciones de completa oscuridad donde permanecieron durante un período de 30 días.

\section{Efecto de la 6 - Bencilaminopurina (BAP) en la proliferación}

Con el propósito de lograr la proliferación de los brotes de E. pellita, se evaluó el efecto del regulador de crecimiento BAP, en concentraciones de: $0 ; 0,25 ; 0,5 ; 1 ; 2$ y 4 mg $\mathrm{L}^{-1}$. Se utilizaron brotes individuales con un par de hojas y una longitud promedia de $0,3 \mathrm{~cm}$. La incubación de los explantes se realizó en condiciones de total oscuridad durante 30 días con una temperatura de $28{ }^{\circ} \mathrm{C}$. Se utilizó un diseño experimental completamente al azar donde cada tratamiento tuvo 45 repeticiones y cada repetición consistió en un brote por frasco de cultivo.

Las variables que se evaluaron fueron: número de brotes, longitud de brotes (se tuvieron en cuenta brotes mayores a $0,3 \mathrm{~cm}$ ), masa fresca y masa seca. En la medición de la variable masa fresca se tomaron los clúster luego del ensayo con las concentraciones de BAP, y se procedió a pesar el material producto del experimento. La masa seca se obtuvo luego de pesar los mismos clúster, identificados y sometidos a un proceso de secado en estufa durante 72 horas a una temperatura constante de $72{ }^{\circ} \mathrm{C}$. 
Efecto del Ácido Indol Butírico (AIB) sobre enraizamiento in vitro

Los brotes que tenían entre $1-2 \mathrm{~cm}$ de longitud se sembraron directamente en el medio de cultivo, compuesto por las sales minerales y vitaminas del MS, y la auxina AIB en concentraciones de $0 ; 0,3 ; 0,5$ y $1,0 \mathrm{mg} \mathrm{L}^{-1}$. Se empleó un experimento completamente al azar con 40 repeticiones por tratamiento donde cada unidad experimental consistió en un brote por frasco de cultivo. Los brotes se incubaron a una temperatura de $24^{\circ} \mathrm{C}$ y un fotoperiodo de 12 horas luz y 12 horas oscuridad. Las variables dependientes correspondieron a: porcentaje de enraizamiento (brotes que presenten por lo menos una raíz), número de raíces, altura de los brotes y número de hojas. Los datos registrados como porcentajes se transformaron a arcoseno $X$.

\section{Aclimatización}

Para el desarrollo de esta fase, se emplearon plantas con tamaños entre 2 a $4 \mathrm{~cm}$ de longitud. Las variables evaluadas fueron: plantas vivas, longitud de las plantas, número de hojas, longitud de raíces. Los sustratos que se utilizaron en esta fase fueron arena y turba, los cuales se desinfestaron por vapor a 121 ${ }^{\circ} \mathrm{C}$ durante tres horas. Se emplearon bandejas plásticas con compartimentos que posibilitaban el acondicionamiento de la cámara húmeda para garantizar una alta humedad relativa. Se utilizó un diseño experimental completo al azar con tres repeticiones; y la unidad experimental correspondió 30 brotes por semillero.

\section{RESULTADOS Y DISCUSIÓN}

\section{Establecimiento de brotes in vitro}

Los brotes obtenidos de plantas desarrolladas en condiciones de invernadero presentaron un $80 \%$ de prendimiento a partir de la segunda semana de establecimiento bajo condiciones in vitro. La incubación de los explantes en total oscuridad y el tamaño de los explantes (ocho centímetros) permitieron que los brotes lograran diferenciarse sin presentar problemas de necrosis y oxidación después de 30 días. Los brotes se originan principalmente de la zona media hacia la base del brote, debido a la ausencia de luz los brotes son completamente etiolados y de color pálido (Figura 1A); sin embargo, cuando se colocan en condiciones de luz adquieren la coloración verde normal. George (1996) informa que los explantes desarrollados en completa oscuridad tienden a presentar menor contaminación debido a que los microorganismos contaminantes tienen unas condiciones poco favorables para su desarrollo.

\section{Evaluación de diferentes concentraciones de \\ BAP en la fase de proliferación}

Uno de los objetivos importantes que se pretenden lograr al iniciar un proceso de micropropagación de una especie forestal, es obtener de manera eficiente su multiplicación vegetativa. E. pellita, al igual que otras especies de eucaliptos, tienen la habilidad de crecer in vitro en condiciones de total oscuridad (escotomorfogénesis), donde los brotes se tornan etiolados y su energía la invierten en una rápida elongación de los tallos, sin la expansión foliar (Castro y González 2001). En ensayos preliminares en nuestro laboratorio (datos no presentados), cuando los brotes se colocaron en condiciones de iluminación con un flujo de fotones fotosintéticamente activos (FFF) de $80 \mu \mathrm{mol} \mathrm{m} \mathrm{m}^{-2} \mathrm{~s}^{-1}$, en los diferentes tratamientos con BAP se presentó proliferación, 
pero en todos los casos se formaron rosetas con muy poco desarrollo. Por esta razón, todos los materiales se incubaron bajo condiciones de total oscuridad (Figura 1B). Trascurridos 30 días los brotes se colocaron en condiciones de luminosidad como la expresada anteriormente, después de 15 días estos mostraron formación de clorofila y una coloración verde (Figura 1C).

Los explantes cultivados en el medio de cultivo MS enriquecido con las diferentes concentraciones de BAP presentaron proliferación en un lapso de 30 días después de su transferencia (Tabla 1). Para la variable brotes/explante (Figura 2A), se obtuvo el mejor resultado cuando se adicionaron al medio de cultivo las dosis más bajas de BAP 0,25 y 0,5 mg L-1, lográndose 8,83 y 7,88 brotes/explante respectivamente.

En cuanto a la longitud de los brotes, los tratamientos comprendidos entre 0-1 mg $\mathrm{L}^{-1}$ de BAP no presentaron diferencias significativas, con valores de 0,68 y 0,53 respectivamente; concentraciones más altas, limitan la elongación (Figura 2B). Resultados similares obtuvieron Bennett et al (1994) en la propagación de E. globulus y atribuyen esta respuesta a la inhibición de las auxinas endógenas.

Tabla 1. Efecto de diferentes concentraciones de ácido indolbutírico sobre el porcentaje de enraizamiento, número de raíces y la longitud de la raíz en E. pellita

\begin{tabular}{lccc}
\hline AIB $\mathbf{~ m g ~ L}^{-1}$ & Enraizamiento $(\%)$ & Número raíces & Longitud raíces(cm) \\
\hline 0 & $0 \mathrm{c}$ & $0 \mathrm{C}$ & $0 \mathrm{c}$ \\
0,3 & $5,0 \mathrm{c}$ & $0,08 \mathrm{C}$ & $0,02 \mathrm{C}$ \\
0,5 & $60,0 \mathrm{~b}$ & $2,1 \mathrm{~b}$ & $0,72 \mathrm{~b}$ \\
1,0 & $80,0 \mathrm{a}$ & $3,8 \mathrm{a}$ & $1,35 \mathrm{a}$ \\
2,0 & $50,0 \mathrm{~b}$ & $2,0 \mathrm{~b}$ & $0,5 \mathrm{~b}$ \\
\hline
\end{tabular}

Todos los datos representan la media de 40 repeticiones. Los tratamientos con letras diferentes presentaron diferencias significativas para $\mathrm{p}<0,05$ para test de Duncan
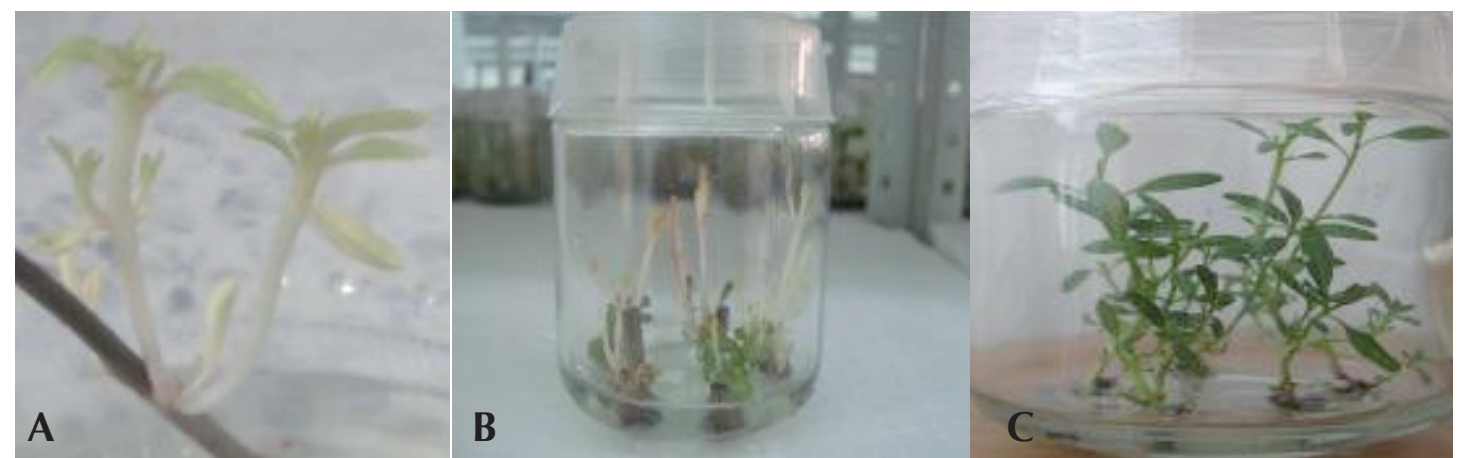

Figura 1. Efecto de la incubación en condiciones de total oscuridad de brotes de eucalipto durante las fases de establecimiento y proliferación. A) Inducción de brotes en segmentos nodales B) Elongación de brotes en medio de cultivo MS enriquecido con $\operatorname{BAP}\left(0,25 \mathrm{mg} \mathrm{L}^{-1}\right)$. C) Cuando los brotes se colocan en condiciones normales de luminosidad inician proceso normal de formación de clorofila. 

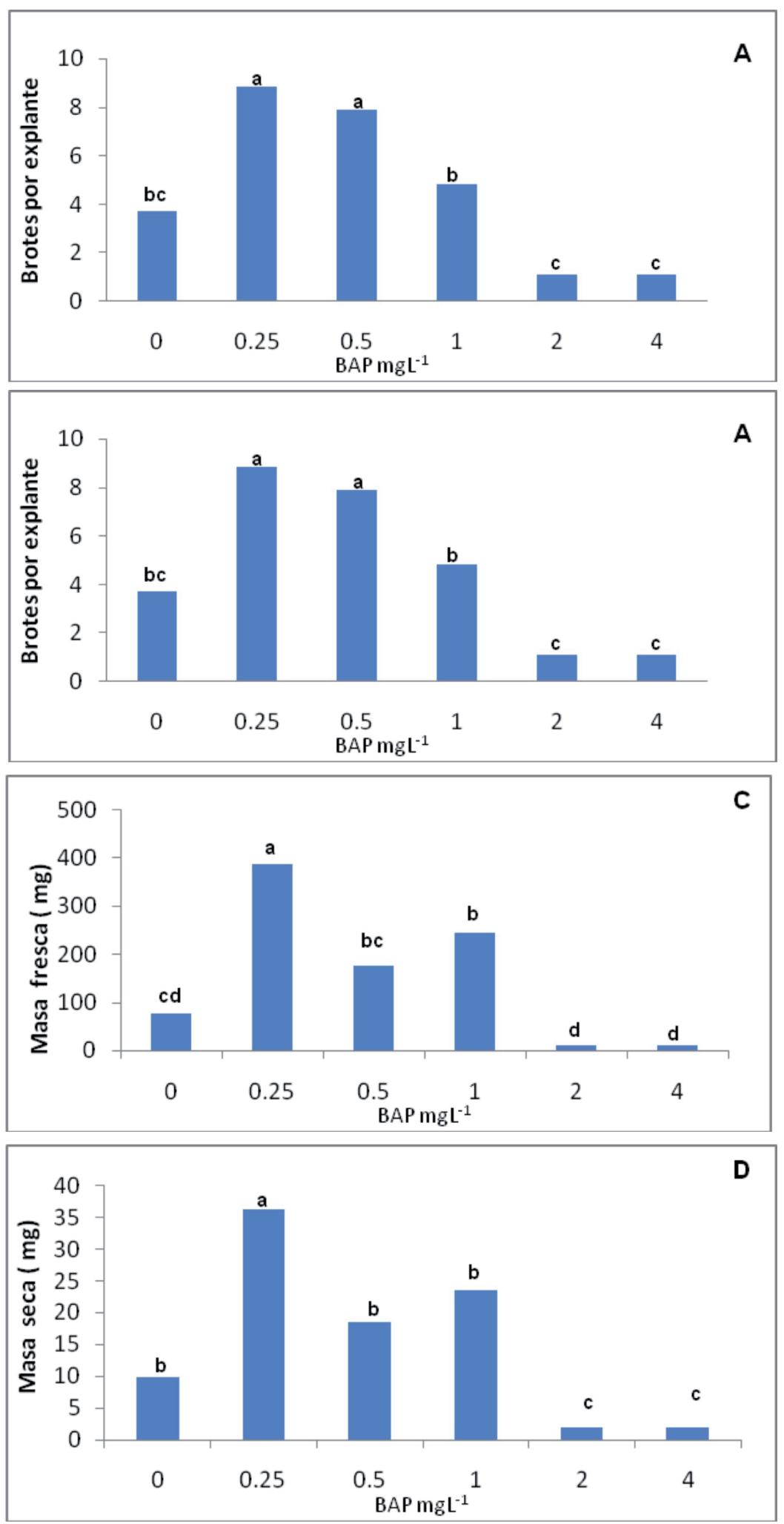

Figura 2. Efecto del BAP sobre: (A) Brotes por explante, (B) longitud de brotes, (C) masa fresca, (D) masa seca. Todos los datos representan la media de 45 repeticiones. Los tratamientos con letras diferentes presentaron diferencias significativas para $\mathrm{p}<0,05$ para test de Duncan 
Respecto a las masas fresca y seca se observan los mayores valores cuando se empleó 0,25 mg $\mathrm{L}^{-1}$ de BAP, guardando relación con el mejor resultado obtenido para el número de brotes presentado con la misma concentración (Figuras 2C y 2D).

Los resultados en la fase de proliferación coinciden con los obtenidos en Eucalyptus grandis por Correia (1993), quien obtuvo altas tasas de brotación, al trabajar con E. grandis, E. grandis $\times$ E. urophylla y E. urophylla $\times$ E. grandis, empleando concentraciones bajas de $\operatorname{BAP}\left(0,3-0,5 \mathrm{mg} \mathrm{L}^{-1}\right)$. En el caso de $E$. nitens la utilización de $0,25 \mathrm{mg} \mathrm{L}^{-1}$ permitió obtener la mejor respuesta de multiplicación (Gomes y Canhoto 2003). El efecto negativo de las dosis relativamente altas de 6-BAP en la multiplicación de este género ha sido observado por Caravalho (1988) quien planteó que concentraciones de 6-BAP superiores a $0,75 \mathrm{mg} \mathrm{L}^{-1}$ fueron perjudiciales para el desarrollo de los brotes y disminuyeron el coeficiente de multiplicación por los bajos índices de crecimiento que experimentaron los explantes. Por lo tanto, de acuerdo con los resultados obtenidos la utilizaciónde BAP $\left(0,25 \mathrm{mg} \mathrm{L}^{-1}\right)$ presentó la mejor respuesta en las variables evaluadas.

\section{Evaluación del efecto del AIB sobre enraizamiento in vitro}

Los resultados obtenidos permitieron determinar que se requiere la presencia de la auxina en el medio de cultivo para la formación de raíces en los brotes de E. pellita. La tabla 1 muestra que cuando se utilizó $1 \mathrm{mg} \mathrm{L}^{-1}$ de AIB se logró un $80 \%$ de brotes que formaron raíces; de igual manera, con esta concentración se logró la formación del mayor número de raíces y su mayor longitud. Cuando se utilizó una concentración mayor se disminuyó el porcentaje de enraizamiento.

Warrag et al. (1991) encontraron que el AIB ha sido exitoso en la elongación de $E$. grandis. Las auxinas promueven el crecimiento $\mathrm{O}$ elongación de las plantas mediante dos vías: por incremento de la extensibilidad de la pared celular debido a la secreción de iones de hidrógeno dentro y a través de ésta, permitiendo finalmente que las células se expandan debido a una mayor absorción de agua y por un efecto en el metabolismo del $A R N$, que induce posiblemente la trascripción de moléculas de ARN mensajero. Este ARNm codifica proteínas necesarias para el desarrollo de las plantas, según se presume de los resultados alcanzados.

De acuerdo con autores como Berrueto et al. (1999) en E. grandis X E. urophylla, Agramonte (2001) en E. grandis, Martinez et al. (2005) en E. urophylla y Joshi et al. (2003) en E. tereticornis, el empleo del AIB en concentraciones hasta de $1 \mathrm{mg} \mathrm{L} \mathrm{L}^{-1}$, es el regulador de crecimiento más eficiente para el enraizamiento de algunas especies de eucaliptos.

\section{Aclimatización}

La aclimatización de plántulas obtenidas por cultivo de tejidos es uno de los pasos más importantes en el proceso demicropropagación. En el presente caso de E. pellita en la figura 3 todas las variables evaluadas presentaron diferencias estadísticamente significativas. Con relación al porcentaje de supervivencia utilizando turba como sustrato se logró un 100\% de adaptación de las plántulas de $E$. pellita, mientras que cuando se utilizó arena 
se logró un 11,3\% de supervivencia (Figura 3A), lo cual se debió principalmente al rápido drenaje del agua lo que ocasiona una alta deshidratación. De igual manera, el número de hojas y la longitud de la planta tuvieron los mejores resultados con la utilización de la turba (Figuras 3B, 3C). Fuera del medio de cultivo las plántulas de E. pellita son altamente susceptibles al desecamiento de las hojas en pocos segundos si no se mantienen en condiciones de alta humedad. Es por eso que se deben trasplantar utilizando un sistema de niebla intermitente o utilizar una técnica adicional de abrir parcialmente los
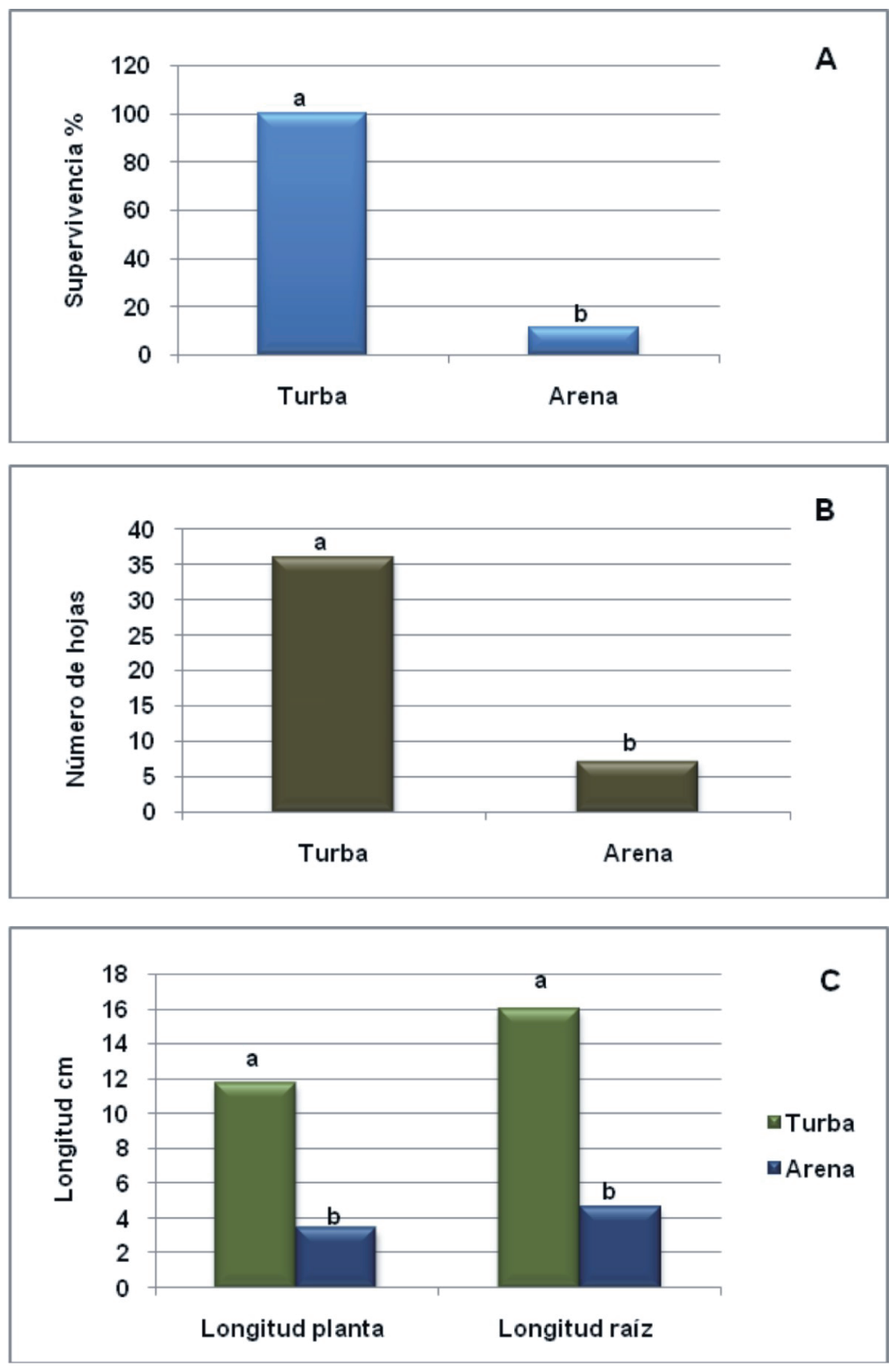

Figura 3. Efecto del sustrato en la aclimatación de plántulas de E. pellita producidas in vitro en la fase de invernadero sobre; (A) supervivencia, (B) número de hojas, (C) longitud de planta y longitud de raíz. Todos los datos representan la media de tres repeticiones (la unidad experimental consistió en 30 brotes por semillero). Los tratamientos con letras diferentes presentaron diferencias significativas para $\mathrm{p}<0,05$ para test de Duncan 
recipientes de cultivo (Noda 2000). El proceso de micropropagación de E. pellita se adaptó para la reproducción clonal de 34 árboles plus, los cuales se han utilizado como plantas madres para el establecimiento de minijardines clonales.

\section{CONCLUSIONES}

En el presente trabajo de investigación se propagó clonalmente e in vitro árboles plus de Eucalyptus pellita. La incubación de los explantes bajo condiciones de total oscuridad permitió la diferenciación y elongación de los brotes durante las fases de establecimiento y proliferación. Durante la fase de multiplicación, con la utilización de BAP en una concentración de 0,25 $\mathrm{mg} \mathrm{L}^{-1}$ se logró obtener la mejor respuesta de proliferación (8,83 brotes por explante) y contenidos de masas seca y fresca. Durante el enraizamiento con la utilización de AIB (1 $\left.\mathrm{mg} \mathrm{L}^{-1}\right)$ se obtuvo un $80 \%$ de enraizamiento; posteriormente, cuando los brotes se sembraron en turba presentaron un $100 \%$ de supervivencia.

\section{AGRADECIMIENTOS}

Los autores agradecen al ingeniero Guido Gasca y al equipo técnico de Reforestadora de la Costa "REFOCOSTA S.A" localizada en Villanueva (Casanare) por su apoyo en los procesos de selección clonal y revigorización de E. Pellita. Este trabajo tuvo el apoyo financiero del Ministerio de Agricultura y Desarrollo Rural de Colombia.

\section{REFERENCIAS}

Agramonte P. D. 2001. Micropropagación del Eucalyptus grandis (Hill ex Maiden) a partir de segmentos nodales. Artículo científico Biotecnología Vegetal 1(2), 109-114.

Berrueto, P.; Machado, A.; Carvalheira, S.; Brasileiro, C. 1999.Plant regeneration from seedling explants of Eucalyptus grandis X E. urophylla. Plant Cell, Tissue and Organ Culture 56: 17-23.

Bennett, I., McComb, J., Tonkin, C., A. J. McDavid. 1994. Alternating cytokinins in multiplication media stimulates in vitro shoot growth and rooting of Eucalyptus globulus Labill. Annals of Botany 74: 53-58.

Castro, D.,J.L. Gonzalez. 2001. Control de condiciones ambientales y medio de cultivo para la propagación de Eucalyptus grandis en el sistema de inmersión temporal. Actual Biol 23(75): 13-18.

Carvalho, D. 1988. Micropropagacao de Eucalyptus grandis Hill ex Maiden a través da cultura in vitro de segmentos nodais.Trabajo de grado de Maestría. Brasil: Escuela Superior de Agricultura de Larvas. http://wwwrevista. ibp.co.cu/component/.../30 bv0397-01-12109-114.html[Enero 3 de 2010]

Correia, D. 1993. Crescimento e desenvolvimento de gemas na 
multiplicacao de Eucalyptus spp. In vitro em meio da cultura liquido e solido. Trabajo de grado de maestría. Piracicaba. São Paulo, Brasil. http:// www.ipef.br/publicacoes/scientia/ nr48-49/cap11.pdf[Enero 5 de 2010].

Gasca, G. 2006. Informe técnico de investigación del Eucalyptus pellita En Villanueva - Casanare Refocosta. S.A. Colombia, p. 15.

George, E.F. 1996. Plant propagation by tissue culture part 2. In practice. 2nd edition. Exegenetics Limited England, p 976-978.

Gomes, F., Canhoto, J. 2003. Micropropagation of Eucalyptus nitens $M$ (Shining gum). In vitro cellular and developmental biology. 39: 316-321.

Gupta PK, Mehta UJ y Mascarenhas AF. 1983 A tissue culturemethod for rapid clonal propagation of mature trees of Eucalyptus torelliana and Eucalyptus camaldulensis. Plant Cell Rep. 2: 296-299

Joshi, I., Bisht., P., Sharma, K., Uniyal, D. 2003. In vitro Clonal Propagation of Mature Eucalyptus F1 Hybrid(Eucalyptus tereticornis SM. x E. grandis HILL ex. MAIDEN). Silvae Genetica 52: 3-4.

Martínez, R., Azpíroz, H., Rodríguez, J., Cetina, V., Gutiérrez, M., Sahagún, J. 2005. Micropropagación clonal in vitro en Eucalyptus grandis y $\mathrm{E}$. urophylla. Ra Ximhai 1(1): 111 - 130

McComb, JA., IJ. Bennett. 1986. Eucalypts (Eucalyptus spp.). In: Bajaj YPS (ed.) Biotechnology in agriculture and forestry, vol 1. Trees 1. Springer Verlag. Berlin, Heidelberg New York, p 340-362.

Murashige T. y Skoog F. 1962. A revised medium for rapid growth and bioassays with tobacco tissue cultures. Physiologia Plantarum 15:473-497.

Noda, J. L. 2000. Propagación clonal in vitro de E. pellita. Centro de estudio de Biotecnología de las plantas. Cuba: Universidad Pinar del Río, p 29-33.

Trindade H y M. S. Pais. 1997. In vitro studies on Eucalyptus globulus rooting ability. In Vitro Cellular and Developmental Biology Plant, 33:1, 1 - 5.

Warrag E.L., M.S. Lesney., D.L. Rockwood. (1991). Nodule culture and regeneration of Eucalyptus grandis hybrids. Plant Cell Reports, 9:586589.

Watt M. P., P. Berjak, A. Makhathini y F. Blakeway. 2003. In vitro field collection techniques for Eucalyptus micropropagation. Plant Cell, Tissue and Organ Culture, 75: 233-240. 